\title{
The Model of Consumer's Switching Intention from Conventional Food to Organic Food: An Experimental Design Study
}

\author{
Heru Irianto \\ Faculty of Agriculture, Department of Agribusiness, Sebelas Maret University, Indonesia \\ Email : irian_her@yahoo.com
}

Tulus Haryono

Budhi Haryanto

Asri Laksmi Riani

Faculty of Business and Economic, Department of Management, Sebelas Maret University, Indonesia

\section{Doi:10.5901/mjss.2015.v6n3s2p588}

\section{Abstract}

The purpose of this research is to design a model of intention switch from conventional food to organic food. The research model is based on the results of preliminary studies, which further confirmed through relevant journals from previous studies. Experimental design was chosen to perform some treatment of the observed variables, namely 2 ( attributes : high , low ) x 2 ( inconveniences : high, low ) x 2 ( motivation to elaborate information : high, low ) factorial design. The participants were 200 undergraduate students at the University of Sebelas Maret were selected through an announcement posted on the bulletin board. Hierarchical multiple regression analysis were selected to analyze the relationship between variables were hypothesized. This study shows that the intention to switch from conventional food to organic food is influenced by product attributes, inconvenience and attitudes towards organic food moderated by motivation to elaborate information. The theoretical implications of this study helps to understand the basic concepts of consumer switching behavior.

Keywords: Organic Food; Attitude; Intention to Switch; Experiment

\section{Introduction}

The phenomenon of intention to switch from conventional food to organic food is still relatively important debate. This is indicated by the absence of a model that is able to explain the phenomenon in all situations, because each model depending on the object and the settings that are relevant to the research objectives to be achieved so that the implications of each model are limited generalizations. The literature review shows that diversity occurs because of differences in the object models, theories, and research methods used (Mittal and Lassae, 1994; Keaveney, 1995; Colgate and Lang, 2001). In addition, previous studies focused aim is to uncover the motive switch and avoid any switch (Keaveney, 1995; Colgate and Lang, 2001; Siddiqui, 2011). Therefore, in this study will be studied theoretically the process of switching from conventional food to organic food to encourage consumers to switch with reference to the intention of turning a product models.

Model intention to switch from conventional food to organic foods in this study was built by relying on the observation of the techniques focus group discussion (FGD), which was later confirmed by the relevant journals. In the resulting model is further conducted experiments to determine the effectiveness of the model in explaining the intention to switch. Based on these observations identified that the model is based on five variables as the following observations :

The first variable is the product attributes. Variable product attributes basically shows the characteristics and benefits of the product (Engel, et al., 1992). Attribute characteristic differences between conventional and organic food is reflected in consumer confidence that organic food is more durable, more delicious (Wandel and Bugge, 1997), and free of pesticides (Swanson and Lewis, 1993; Lea and Worsley, 2005). In the context switching, attributes the differences will affect the attitudes and intentions of consumers switch i.e. the higher the perception of differences between the product attributes of a product to its alternatives, consumers are likely to be positive about the switch (Herr, et al., 1991; Rimal and Fletcher, 2000) and intends to switch to alternative products (Thapa, 2012; Awogbemi, et al., 2012). 
The second variable to be considered as a determinant of intention to switch is an inconvenience. In terms of the intention to switch from conventional food to organic food, inconvenience can be a difficult obstacle searched find, the price difference is high (Zanoli and Naspetti, 2002; Chinnici, et al., 2002) and at least an alternative option (Chinnici, et al ., 2002) and high switching costs (Anton, et al., 2007). In the context switching, the difference inconvenience will affect consumer attitudes and intentions to switch i.e. the higher the difference inconvenience in obtaining alternative products than the original product, the consumer not to switch (Keaveney, 1995; Grace and O'Cass, 2001).

The consumer's motivation to elaborate information is the third variable observed. Motivation elaborate on the information originated from the general concept of motivation to do that in the context of the development of a switch in the object being observed. In the context of product switching, motivation to elaborate information is defined as the individual motivation to elaborate information (Savolainem, 2012). Consumers who want to switch from one product to the alternative will be evaluated by comparing the knowledge of old products and information relating to new products, so that they can decide on a product that can meet their needs (Lai, 1991). Consumers with high motivation to elaborate on the information that will seek to improve and deepen the information obtained; Conversely, consumers with low motivation to elaborate information will not do. The expansion and deepening of information impacting the increasing consumer awareness about the required product. This condition will affect strengthen or weaken the attitudes and intentions of consumers to switch. Previous research on the role of motivation variable information elaborates on the relationship attitudes and intentions still showed inconsistencies. The inconsistency is due prior knowledge possessed different consumers. At high initial knowledge of new information would be likely to cause expansion, being in possession of a low initial knowledge of new information are less likely to expansion (Chiu and Chiu , 2012). These conditions allow this study to review it to get the consistency of beliefs about the role of motivation to elaborate information on attitudes and intentions to switch from conventional food to organic food.

Attitude and intention to switch the variable to the fourth and fifth were observed. Attitude refers to the degree of good or not good evaluation of a person to an object that influence behavior. The higher being supportive behavior, the higher the intention to carry out the behavior (Ajzen, 1991). Past studies regarding the relationship attitudes and intentions still shows inconsistency. This inconsistency can be seen from the significant positive relationship (Wen, 2010; Chen and Chao, 2011; Thapa, 2012) , and not significant (Kalafatis, et al., 1999; Vermeir and Verbeke, 2006).

Based on the background described then this article aims to examine the effect of variable product attributes and inconvenience to switch to organic food attitudes, influence the attitude variable switch on the intention to switch to organic food. This study also aimed to test the effect of moderating variables motivation to elaborate information on the relationship between the variables of product attributes and inconvenience to shift attitudes and motivation variables moderating influence elaborate information on the relationship between the variables of attitude shift towards intention to switch to organic food.

\section{Literature Review}

In this study, the approach used is cognitivist perspective by considering, first, the observed variables in the study were in the form of product attributes, inconvenience, attitude and intention to switch the cognitive element. Variable product attributes and inconvenience is an element of thinking, an attitude variable elements of feeling and intention to switch an acting element. Second, the use of behavioral cognitivist approach used for this study aims to reveal the individual's perception of an object. Third, previous studies on consumer behavior shows that the model describes the relationship of thinking, feeling, and acting has been proven to accurately predict accurately the behavior of the purchase of certain products (Ajzen and Fishben, 1980; Sheppard, et al., 1988; Homer, 1990; Armitage and Conner, 2001)

\subsection{The effect of product attribute (PA) on switching attitude}

Product attributes, according to Mowen and Minor (1997), is a characteristic or feature that may be owned or not owned by the object. Objects that are intended can be a product, person, company (corporate), and everything that an individual has the confidence and attitude.

Based on quality, product attributes can be divided into three categories : search attributes, experience, and credens (Grunert, 2002). Search attributes are all dimensions of quality of the products that can be known prior to purchase, for example, price, brand, nutritional information and production information. Attributes of experience can be known after making a purchase and can be felt while taking it, for example, taste, freshness, and convenience. While credens attribute is a dimension that can not be found before or shortly after consuming the product, for example health benefits, natural and environmentally friendly products, the value of the exclusive and production processes. 
Characteristics of organic food has been believed to be a better food than conventional food, which is reflected on the attributes of more durable, more delicious (Wandel and Bugge, 1997), free of pesticides / chemicals substances freeness (Swanson and Lewis, 1993; Lea and Worsley, 2005), and more secure (food safety) (Vindigni, et al., 2002; Ozcelik and Ucar, 2008). This condition indicates that the attribute category as a differentiating factor of the non-organic foods are more appropriate organic is an attribute of experience and credens.

Propositions put forward to describe the relationship between product attributes and attitudes switch based on the phenomenon that is likely to have a positive relationship patterns, ie the higher the consumers' perception of difference attributes, the higher the positive attitude to switch to organic foods (Herr, et al., 1991; Rimal and Fletcher, 2000). The reasons underlying the positive relationship patterns are described as follows.

First, basically consumers act rationally in deciding to switch from one product to another to satisfy their wants and needs. The consumer will be evaluated by comparing the knowledge of the products are usually consumed with information relating to new products, so they can decide which products can meet his / her needs (Lai , 1991). If this comparison indicates a significant difference in attributes, consumers tend to have a positive attitude to switch (Lee, et al., 2001).

Secondly, there is the perception that organic food is healthier, safer, and more environmentally friendly than conventional food (Vindigni, et al., 2002; Tarkianen and Sundqvist, 2005; Chen , 2009). It encourages consumers to have a positive attitude towards organic food. Thus, the formulation of the first hypothesis is :

$\mathrm{H} 1$ : The higher the consumer 's perception of the differences in the attributes of the product, the higher the positive attitude to switch to organic foods.

\subsection{The effect of inconvenience (IC) on the switching attitude}

Inconvenience is a troubling incident or complicate the customer. In consuming a product, inconvenience negative effect on attitudes (Olsen, 2007), and the level of customer satisfaction (Ninh, 2010). Meanwhile, in the context of the intention to switch, inconvenience refers to all the issues that vex or complicate the customer made the decision to switch (Grace and O'Cass, 2001). Inconvenience may be the time it takes to access and obtain a product perceived longer than perceived, change the time and place of service, waiting times, lack of attention (Keaveney, 1995), the difficulty to find the product, the price is expensive (Zanoli and Naspetti, 2002; Chinnici, et al., 2002), the low availability (Kalafatis, et al., 1999; . Magnusson , 2001; Vindigni, et al., 2002; Tarkianen and Sundqvist , 2005; Chen , 2009) and alternative products are limited (Chinnici, et al., 2002 ) and high switching costs (Anton, et al., 2007).

Propositions put forward to describe the relationship between inconvenience and attitude switch is based on the phenomenon of negative patterns of relationship, ie the higher the perception of the difference inconvenience in product acquisition, the lower the positive attitude to switch to organic foods. The reasons underlying the negative relationship patterns are described as follows.

Basically, to switch from one product to another product, the consumer will consider whether or not there an extra effort to get these alternative products. If need significant additional effort, there will be no switching. Additional efforts to obtain alternative products such an inconvenience, which in the context of switching intentions may be difficult to obtain the product, the price is high (Zanoli and Naspetti, 2002; Chinnici, et al., 2002), the low availability (Kalafatis, et al., 1999; Magnusson, 2001; Vindigni, et al., 2002; Tarkianen and Sundqvist, 2005; Chen, 2009) and lack of alternative options (Chinnici, et al., 2002). Conversely, if the extra effort to get alternative products are not perceived differently, consumers tend to switch ( Grace and O'Cass, 2001; Gerrard and Cunningham, 2004). Thus, the formulation of the second hypothesis is:

$\mathrm{H} 2$ : The higher the perception of the difference inconvenience in obtaining the product, the lower the positive attitude of consumers to switch to organic foods.

\subsection{Information elaborating motivation (IEM) / Motivation elaborate information}

Motivation is a series of psychological processes that led to the movement, direction, and persistence of voluntary attitude that leads to the destination (Kreitner and Kinicki, 2008). In this study, the motivation question is consumer motivation to elaborate on the information, defined as an individual incentive to elaborate information about the choice of purchasing the product (Rothman, et al., 1993; Maoz and Tybout, 2002; Harrell, 1986; Savolainem 2012). Basically, every consumer, before deciding to buy a product, have the possibility to have initial information about it (Chiu and Chiu, 2012). For example, the consumers consume spinach vegetable to get iron source or consume egg to get protein benefit it contains. However, while choosing from a variety of the same product, consumers will seek to expand the information 
about the product to be consumed. The more important of these products to consumers, businesses increasingly information intensive search. This gives a signal on marketers to motivate consumers to elaborate information related to product attributes. Information about product attributes are important information to determine product choice among options available products because knowledge about the attributes of the product may change the attitudes of consumers towards a product (Cacioppo, et al., 1994).

Propositions put forward is that if the consumers' information elaborating motivation is high, the consumers' attempt of conceiving and evaluating the product attribute will improve, thereby the relationship of product attribute to switching attitude will be stronger. The followings are the reason underlying the positive relationship pattern.

Consumers decide to switch from one product to another if more beneficial (Lee, et al., 2012). This indicates the need for marketers to provide more extensive information about the products on offer, and is able to motivate consumers to elaborate on the information provided. This is consistent with the assumption that the Elaboration Likelihood Model $(E L M)$ is that when consumers have the ability and motivation to expand the information enabling well elaborated information that is expected to strengthen the positive attitude of consumers towards a product (Petty, et al., 2004). Thus, the hypothesis is formulated as follows:

H3: The higher the consumer motivation to elaborate information, further strengthening the influence of the perception of product attributes the difference to the positive attitude of consumers to switch to organic food .

One of the things that consumers consider in choosing alternative products is convenience in obtaining and consuming (Berry, et al., 2002). This means that if a product is getting to have a high convenience level, will further encourage consumers to be positive choose the product compared to other products. In harmony with these opinions, it can be assumed that if to obtain alternative products require low inconvenience increasingly encouraging consumers to be positive switch (Keaveney, 1995; Grace and O'Cass, 2001). These conditions provide a signal for marketers to provide information to consumers that to obtain alternative products, no significant additional effort or inconvenience product has a low, and at the same time motivate consumers to elaborate on the information. Information Elaboration is expected to improve consumer understanding that there is only a slight difference of inconvenience in obtaining organic food and conventional food, so it can change the attitude of consumers to switch.

Propositions put forward is that if to obtain consumer products have a high motivation to elaborate information will inconvenience consumer businesses to understand and evaluate the inconvenience in obtaining these products, so consumers will know the difference inconvenience in obtaining organic food and conventional food. These conditions will weaken the relationship inconvenience obtain a product with an attitude Switch. The reasons underlying the negative relationship patterns are described below.

Previous research states that in order to obtain organic food facts is not easy and need extra effort because of various constraints such prices tend premium, low availability (Zanoli and Naspetti , 2002; Chinnici, et al., 2002) and limited alternative options (Chinnici, et al., 2002), and the high cost of switching (Anton, et al., 2007). However, in order to live a healthy life and preserve the environment, many consumers consume organic food (Wandel and Bugge, 1997; Swanson and Lewis, 1993; Lea and Worsley, 2005; Ozclik and Ucar, 2008). These conditions show marketers that marketers should be able to convince and motivate consumers to elaborate to obtain information that organic foods do not require significant additional effort. Thus, the formulation of the hypothesis is as follows :

$\mathrm{H} 4$ : The higher the motivation to elaborate information will weaken the influence of differences in inconvenience for the positive attitude of consumers to switch to organic foods.

\subsection{Attitude (AT)}

Attitude is a process oriented to an individual's action, evaluation, basic knowledge, and relatively consistent perception relating to an object. Attitude is a consistent set of beliefs in an object that makes people tend to treat the object in a certain way (Weigel, 1983).

In the context of product switching, previous studies have shown consistently that attitude has positive influence on intention to switch (Wen, 2010; Chen and Chao, 2011; Thapa, 2012). Propositions put forward to describe the relationship between attitude and intention to switch is based on the phenomenon that a positive relationship patterns, ie the higher the positive attitude of consumers to switch, the higher intention to switch to organic food. The following are the reasons underlying the positive relationship patterns.

Previous research on the relationship attitudes towards organic food purchase intention consistently showed a positive correlation (Saba and Mesina, 2003; Thogersen, 2007; Chen, 2009). This shows that between attitude and intention to switch to switch to organic foods showed a positive relationship. Thus, the formulation of the hypothesis as follows: 

food.

H5: The higher the positive attitude of consumers to switch to organic foods higher intention to switch to organic

In an effort to decide to switch or not to switch, consumers will look for information related to the availability of products that are needed, including in determining the food they consume. Food not only be just to satisfy hunger, but also to maintain health (Saba and Mesina, 2003; Thogersen, 2007; Tarkianen and Sundqvist, 2005; Chen, 2009), even lifestyle (Chen , 2009). High motivation in elaborating information enabling a better understanding of the characteristics of the product to be consumed, so will affect the attitude and intention to switch to alternative products (MaOz and Tybout, 2002). Thus, the formulation of the hypothesis is :

H6: The higher motivation to elaborate on the information, will further strengthen the influence of attitude on the intention to switch to organic foods.

Based on the description of the process of intention to switch consumers from conventional food to organic foods can be prepared a basic framework model as shown in Figure 1.

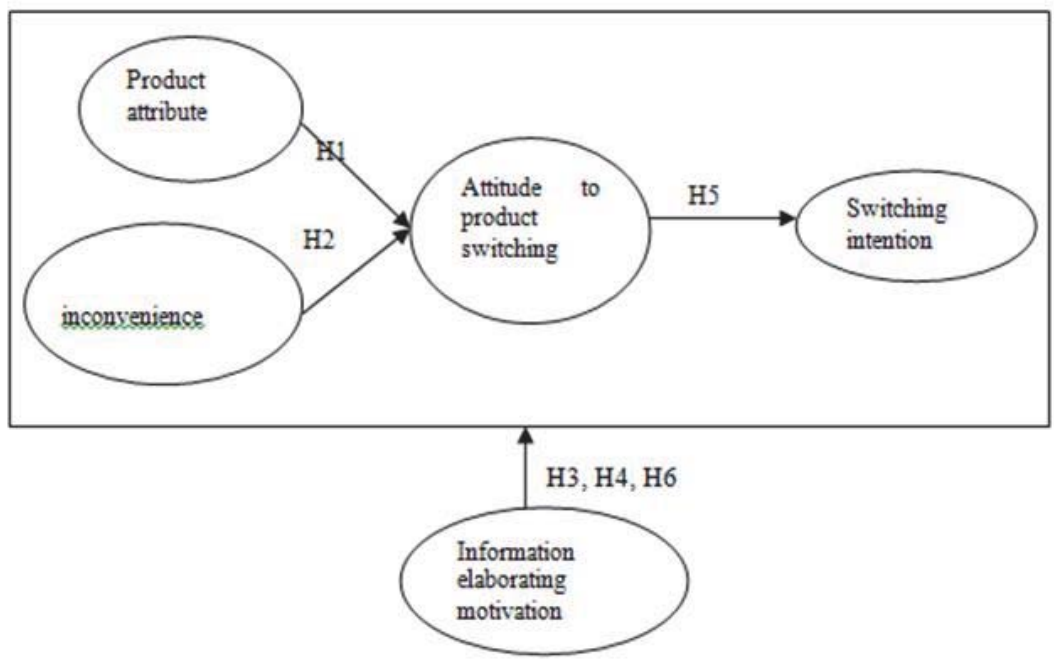

Figure 1. Model the intention to switch from conventional food to organic food

\section{Research Methodology}

\subsection{Desain research}

This study basically aims to test causal relationships between variables were assessed by the independent variable treatment and measuring its impact on the dependent variable. Based on these objectives, the design of appropriate research is experimental designs (Campbell and Stanley, 1966).

Experimental design used was a laboratory experiment, the experiment carried out separately from everyday life that allows researchers not only can manipulate independent variables but also can control other confounding variables with a higher level of control of the experimental field (Ertambang, 2012) .

Experimental design used was between subject factorial consisting of a combination of treatments: 2 ( product attributes : high and low ) 22 (inconvenience : high and low ) $\times 2$ (motivation to elaborate information : high and low), so there are eight experimental groups, who each get a different treatment and stimulus.

\subsection{Stimulus}

Given stimulus are 2 kinds, namely the medium of film and promotional gifts. Film media is designed as an attempt to socialize organic food by organic farmers association to be known to the public, as well as in the form of public opinion on organic food. The film is designed to stimulus attributes socialization high and low inconvenience, while movie disesain public opinion to attribute the low and high inconvenience. Promotional gift is the stimulus material for high information elaborate motivation, while elaborating low motivation are not awarded prizes. Promotional gift giving is intended to motivate participants to want to elaborate on the actual information in a magazine that is designed to give the impression 
of natural product -related information about the attributes and ease of obtaining organic food products. To give a real impression, promotional gifts given in the form of vouchers to eat healthy food.

\subsection{Manipulation Checking}

Manipulation check was conducted to test whether participants' perception of the stimuli used in the experiment was the same as the perception of researchers, as well as the instruments used to test the effect on the dependent variable in our model. The number of participants in the manipulation check set 60 students. Manipulation check results into three treatment variables are presented in Table 1.

Manipulation check results are listed in Table 1 indicate that the design of the third stimulus for treatment variables, namely : product attributes, inconvenience, and motivation elaborate show the diversity of information that can be used in laboratory experiments were conducted.

Table 1: Result of Manipulation Checking

\begin{tabular}{||cccc||}
\hline Variable & Item number & Homogeneity of variance test result & Result of F-test (Between Groups) \\
\hline High attribute & 5 & 0.278 & $\left.237.041^{* *+}\right)$ \\
Low attribute & 5 & & $\left.228.169^{* * *}\right)$ \\
High inconvenience & 5 & 0.454 & $\left.131.935^{* *+}\right)$ \\
Low inconvenience & 5 & 0.933 & \\
High information elaborating Motivation & 5 & & \\
Low information elaborating Motivation & 5 & & \\
\hline
\end{tabular}

Note: $\left.\mathrm{N}=60,{ }^{\star \star *}\right): \mathrm{p}<0.001$, Homogeneity of variance value: $>0.05$; Meaning as insignificant that otherwise is not homogeneous or there is a difference; Meaning as the significant, then the conclusion there is a difference between groups

\subsection{Experimental Procedure}

Laboratory experiments performed procedure is to create an atmosphere like in real conditions (blind experiment) so that participants reacted as in the actual conditions. The study participants consisted of 200 students of the Sebelas Maret University, which is divided into 8 groups of treatment.

\subsection{Statistical Test}

Statistical testing was conducted on the data validity and reliability testing, and hierarchical multiple regression. Validity and reliability of the data is done with the aim to ensure that the data obtained can describe the phenomenon being measured. Meanwhile, a hierarchical multiple regression (HRA) was conducted to determine the causal relationship between the variables studied (Grau, et al., 2001).

\section{Result and Discussion}

\subsection{The result of inter-variable correlational test}

The result of inter-variable correlational test is presented in table 2.

Table 2. The correlation between independent variables

\begin{tabular}{|c|c|c|c|c|c|}
\hline & PA & IC & IEM & IEM *PA & IEM *IC \\
\hline PA & 1.000000 & -0.392991 & 0.034624 & 0.679527 & -0.288304 \\
\hline IC & -0.392991 & 1.000000 & -0.361422 & -0.486505 & 0.526574 \\
\hline IEM & 0.034624 & -0.361422 & 1.000000 & 0.707526 & 0.545937 \\
\hline IEM ${ }^{*} P A$ & 0.679527 & -0.486505 & 0.707526 & 1.000000 & 0.170003 \\
\hline$\left|\mathrm{IEM}^{*}\right| \mathrm{C}$ & -0.288304 & 0.526574 & 0.545937 & 0.170003 & 1.000000 \\
\hline
\end{tabular}

Table 2 shows that there is no correlation between variables are close to 1 , so that the model predictions showed no perfect multicollinearity problems $(r<0.8)$ (Gujarati, 2009). These results indicate that the resulting model can be used to 
predict the phenomenon well.

Besides the issue of multicollinearity, the model predictions should be free from the problems of autocorrelation and heteroscedasticity order predictor models remain blue. In connection with the problem of autocorrelation and heteroscedasticity then used prediction models $\mathrm{ARCH}$ (autoregressive conditional heteroscedasticity) or GARCH (generalized autoregressive conditional heteroscedasticity) (Engle 2001). This model is a regression analysis model developed to accommodate variance is estimated to be the cause of inefficiency and at the same prediction variance can predict the cause of inefficiency models.

\subsection{The Process of Establishing Switching Attitude to Organic Food}

The process of formation of attitudes turn to organic food rests on four issues : (1) the effect of differences in the perception of product attributes on attitude switch to organic food, (2) the effect of differences in the perception of inconvenience on attitudes switch, (3) The effect of interaction of motivation to elaborate information on product attributes differences relationship with attitude switching to organic foods, and (4) The effect of interaction of motivation to elaborate information on the relationship differences inconvenience obtain organic food with attitude switching to organic foods. Based on the four issues forming the attitude switch the hierarchical regression Garch modeled with the following models Hierarchy 1: $A T=$ Garch $+\alpha+\beta_{1} P A+\beta_{2} I C+\beta_{3} I E M+e$

Hierarchy 2: $A T=$ Garch $+\alpha+\beta_{1} P A+\beta_{2} I C+\beta_{3}\left|E M+\beta_{4} P A^{*}\right| E M+\beta_{5}\left|C^{*}\right| E M+e$

The discussion of the results of simultaneous test aims to explain the goodness - of - fit model obtained from the regression model are shown in Table 3.

First, the results of hierarchical regression testing on the model level 1 shows the goodness - of- fit is good ( $F$ - test $=1672.570, p<0.01$ ). This shows that the regression model can be used to explain the phenomenon both attitude switch to organic food. While the value of adjusted $\mathrm{R}^{2}=0.9853$ shows that the variance attitude switch to organic foods can be explained by the variance of product attributes, inconvenience and motivation to elaborate information by $98.53 \%$, while the rest of the variance is explained by other variables outside the model.

Table 3. The result of Hierarchical Regression Analysis with Switching Attitude as Dependent Variable

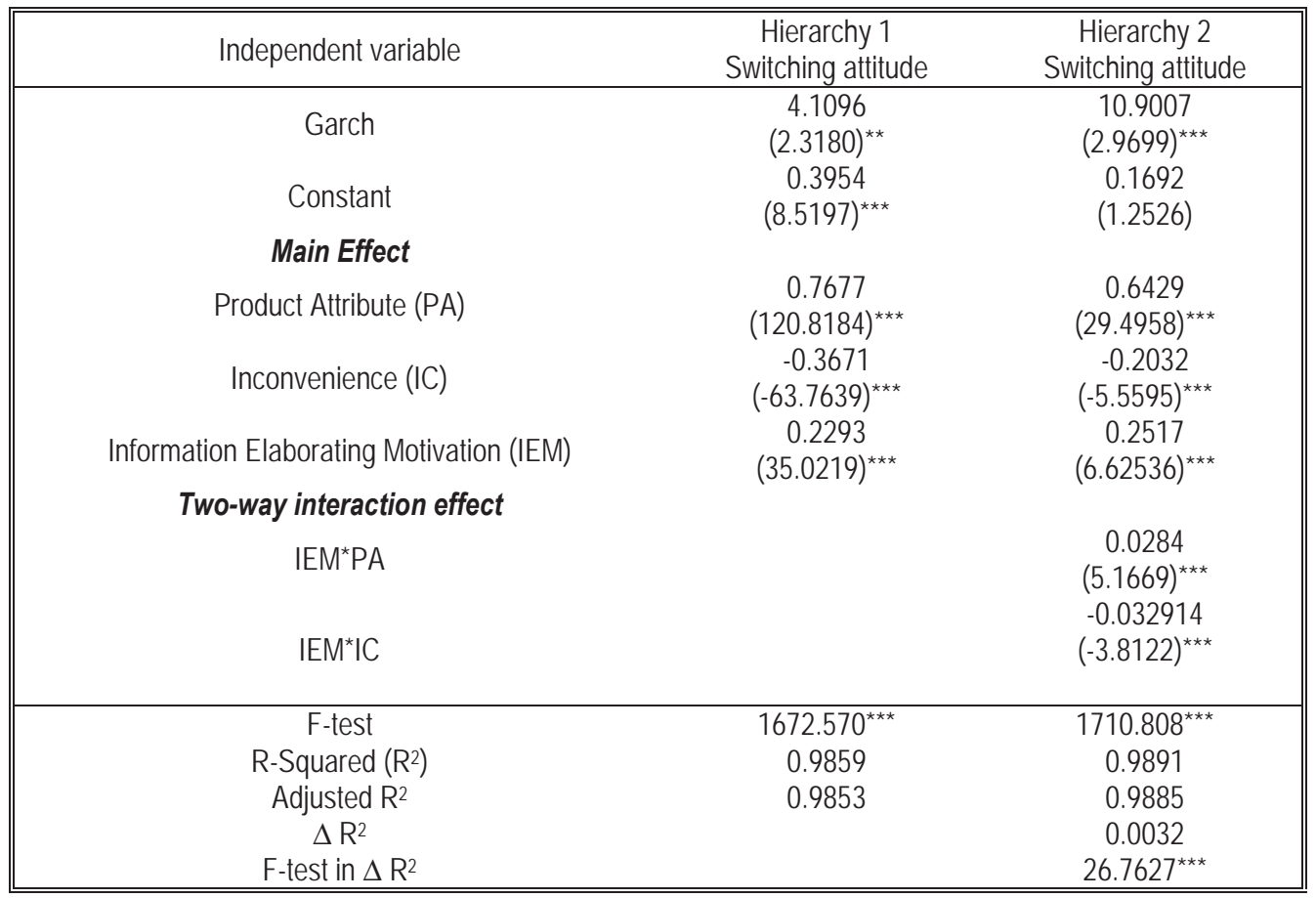

Note : ${ }^{\star} p<0.10 ;{ }^{* \star} p<0.05 ;{ }^{* \star} p<0.01 ; n=200$

Second, the results of hierarchical regression testing on the model of step 2 shows the goodness - of- fit is good (Test $F=$ $1710.808, p<0.01)$. This shows that the regression model can be used to explain the phenomenon both attitude switch 
to organic food. While the value of adjusted $R^{2}=0.9885$ shows that the variance attitude switch to organic foods can be explained by the variance of product attributes, inconvenience and motivation to elaborate information by $98.85 \%$, while the rest of the variance is explained by other variables outside the model.

Furthermore, two-way interaction effects were hypothesized shows the goodness - of- fit is good (test $F$ in $\Delta R^{2}=$ 26.7627, $p<0.01$ ). This indicates that the level 2 models differ significantly from the model level 1 in explaining the complexity of the phenomenon of attitude switch to organic food. This is evident from the value of the $F$ statistic at level 2 $(F$ stat $=1710.808, p<0.01)$ higher in value than the $F$ statistic level $1(F$ stat $=1672.570, p<0.01)$. This condition indicates that the motivation to elaborate information act to strengthen or weaken the relationship between independent and dependent variables in the sequent formation of attitudes switch to organic food.

The discussion on the results of tests of hypotheses about the process of attitude formation switch to organic food further described as follows.

\subsubsection{The effect of different perceptions on Product Attribute on Positive Attitude to switching to Organic Food}

The test results on the first level hierarchical regression showed that the differences in product attributes a positive influence on the attitude of the switch $(\beta=0.7677 ; Z$ value $=120.8184 ; p<0.001)$. This shows that the higher the difference in product attributes, the higher the positive attitude of consumers to switch to organic food. These results support the hypothesis and answer ( $\mathrm{H} 1)$ and in line with the findings of previous studies (Wandel and Bugge, 1997; Swanson and Lewis, 1993; Vindigni, et al., 2002; Lea and Worsley, 2005; Ozcelik and Ucar, 2008; Thapa, 2012 ; Awogbemi, et al., 2012) .

Results of hierarchical regression testing on the second level also showed that differences product attributes positive influence on the attitude switching $(\beta=0.6429 ; Z$ value $=29.4958, p<0.001)$. The pattern of this relationship explains that the higher the difference attributes of organic food products compared to conventional food, the higher the positive attitude of consumers to switch to organic food.

Thus, the results of these tests show the consistency of the effect of different attributes of the product on a positive attitude to switch to organic food.

\subsubsection{The effect of different Inconvenience in obtaining food product on Positive Attitude to switching to Organic Food}

Results of hierarchical regression testing on level 1 indicates that the difference inconvenience negative effect on attitudes switch $(\beta=-0.3671 ; Z$ value $=-63.7639 ; p<0.01$ ). This shows that the higher the perception of the difference inconvenience in obtaining the product, the lower the positive attitude of consumers to switch to organic food. These results support the hypothesis (H2) and in line with the findings of previous studies (Wathne, et al., 2001; Grace and O'Cass , 2001; Gerrard and Cunningham , 2004; Anton, et al., 2007).

The results of the second level hierarchical regression testing also showed that the difference inconvenience negative effect on attitudes switch $(\beta=-0.2032 ; Z$ value $=-5.5595 ; p<0.01)$. The pattern of this relationship explains that this shows that the higher the perception of the difference inconvenience in obtaining the product, the lower the positive attitude of consumers to switch to organic food.

Thus, the results of the test showed that there is consistency in obtaining product inconvenience influence positive behavior and switching to organic food products.

\subsubsection{The effect of interaction variables between Information Elaborating Motivation and Different Perception on Product Attribute on the switching-to-organic food attitude}

The hypothesis that the higher the consumer motivation to elaborate information further strengthens the effect of food on the perception of differences attribute positive attitude switching to organic foods $(\mathrm{H} 3)$ is supported on the second level of testing ( $\beta=0.0284$; Value $Z=5.1669 ; p=0,01)$. The test results support the hypothesis $(\mathrm{H} 3)$ and in line with the results of previous studies (MaOz and Tybout, 2002; Awogbemi, et al., 2012; Chiu and Chiu, 2012). This indicates the moderating influence of motivation to elaborate information that reinforces the pattern of relationships product attribute differences in positive attitudes of consumers switch to organic food.

Thus the findings of this study provide insight to marketers the importance of creating a stimulus that can build consumer motivation to elaborate on the information, so that through the stimulus is expected to increase positive attitudes of consumers switch to organic food. 


\subsubsection{The effect of interaction variables between Information Elaborating Motivation and Different Perception on Inconvenience in obtaining product on the switching-to-organic food attitude}

The hypothesis that the higher the motivation to elaborate information will weaken the influence perception of inconvenience difference in positive attitudes of consumers switching to organic food $(\mathrm{H} 4)$ is supported on the second level of testing $(\beta=-0.0329$; Value $Z=-3.8122 ; p=0.01)$. The test results support the hypothesis $(H 4)$ and in line with the results of previous studies (Maoz and Tybout, 2002; Savolainen, 2011; Chiu and Chiu, 2012). This indicates the moderating influence of motivation to elaborate information weakens the relationship patterns inconveniencet obtain the product on the positive attitude of consumers switch to organic food.

Thus, the findings of this study are practically giving understanding to marketers about the importance of creating a stimulus to encourage the growth of consumer motivation to elaborate on the information and provide an attractive and adequate information, so it can be expected to have an impact on increasing consumer awareness about the advantages of organic food attributes, and at least difference inconvenience in obtaining organic food, so it will have a positive impact on attitudes switch.

\subsection{The Process of Establishing the Switching-to-Organic Food Intention}

The process of forming the intention to switch to organic food depends on two issues : (1) the effect of a positive attitude to switch on the intention to switch to organic foods; and (2) the effect of the interaction of motivation to elaborate information on the relationship positive attitude switch with the intention to switch to organic food.

Based on the two issues forming the intention of turning the hierarchical regression modeled as follows :

Hierarchy 1: IN $=\log ($ Garch $)+a+\beta_{1} A T+\beta_{2} I E M+e$

Hierarchy $2: I N=\log ($ Garch $)+\alpha+\beta_{1} A T+\beta_{2}\left|E M+\beta_{4} A T^{*}\right| E M+e .$. (4)

Results of hierarchical regression hypothesis testing in the process of forming the intention to switch to organic foods is shown in Table 4. This stage begins with a discussion on the results of simultaneous test that aims to explain the goodness - of - fit model obtained in the regression model each level.

First, the results of tests on the regression model hierarchy level 1 shows the goodness - of- fit is good (Test $\mathrm{F}=$ $1163, p<0.01)$. This indicates that the regression model which can be used to explain the phenomenon of intention to switch to organic food properly. While the adjusted $R^{2}=0.9761$ indicates that the intention of switching to organic food products can be explained by the motivation to elaborate information and attitude switch of $97.61 \%$, while the rest is explained by the variance of the variables outside the model.

Table 4. The result of Hierarchical Regression Analysis with Switching Intention as Dependent Variable

\begin{tabular}{|ccc||}
\hline Independent Variable & Hierarchy 1 Switching Intention & Hierarchy 2 Switching Intention \\
\hline Log(Garch) & 0.3460 & 0.0150 \\
& $(5.6851)^{\star \star \star}$ & $(1.5171)$ \\
Constant & 0.9934 & 0.5639 \\
Main Effect & $(4.1325)^{\star \star \star}$ & $(8.1446)^{\star \star \star}$ \\
Attitude (AT) & 0.6494 & 0.3164 \\
& $(37.8755)^{\star \star \star}$ & $(22.1930)^{\star \star \star}$ \\
Information Elaborating Motivation (IEM) & 0.4597 & 0.2088 \\
Two-way Interaction Effect & $(51.0747)^{\star \star \star}$ & $(18.1174)^{\star \star \star}$ \\
IEM ${ }^{\star A T}$ & & 0.1067 \\
F-test & & $(23.3695)^{\star \star \star}$ \\
R-Squared $\left(R^{2}\right)$ & $1163.562^{\star \star \star}$ & 0.97752 \\
Adjusted $R^{2}$ & 0.97697 & 0.97658 \\
$\Delta R^{2}$ & 0.97613 & 0.0005 \\
F-test in $\Delta \mathrm{R}^{2}$ & & $3.7938^{\star \star}$ \\
\hline \hline
\end{tabular}

Note : ${ }^{\star} p<0.10 ;{ }^{* \star} p<0.05 ;{ }^{* \star \star} p<0.01 ; n=200$ 
Second, the results of tests on the regression model hierarchy level 2 shows the goodness - of- fit is good (Test $F=$ $1038.280, p<0.01)$. This indicates that the model can be used to explain the phenomenon well. Meanwhile, the value of the adjusted $\mathrm{R}^{2}=0.9766$ indicates that the intention of switching to organic food products can be explained by the motivation to elaborate information and attitude switch of $97.66 \%$, while the rest is explained by the variance of the variables outside the model.

Furthermore, two-way interaction effects were hypothesized contribute the higher goodness - of- fit test ( $\mathrm{F}$ test at $\Delta$ $R^{2}=3.7938, p<0.01$ ). This indicates that the regression model 2 levels differ significantly from one level regression model to explain the complexity of the phenomenon of intention to switch to organic food products. This condition indicates that the motivation to elaborate information is important that consumers consider to strengthen or weaken the intention to switch to organic food.

The discussion on the results of tests of hypotheses about the process of forming the intention to switch to organic food further described as follows.

\subsubsection{The effect of switching attitude on the switching-to-organic Food intention}

Test results using the first level hierarchical regression showed a pattern of positive influence attitudes towards switching intention $(\beta=0.6494 ; Z$ value $=37.8755, p<0.001$ ). This shows that the higher the positive attitude, the higher intention to switch to organic food. These results support the hypothesis (H5) and in line with the findings of previous studies (Keaveney, 1995; Bansal and Taylor, 1999; Saba and Mesina, 2003; Thogersen, 2007; Chen, 2009; Tung, et al., 2012).

The test results on two levels also showed a positive influence patterns of attitudes to switching intention ( $\beta=$ $0.3164 ; Z$ value $=22.1930, p<0.001)$. The pattern of this relationship explains that the higher the positive attitude switch, the higher the intention of switching to organic food.

Thus, the results of these tests showed a positive attitude switch consistency influence on the intention to switch to organic food. These findings indicate that the attitude switch is forming the intention to switch to organic food.

\subsubsection{The effect of interaction variables between Information Elaborating Motivation and Switching attitude on the switching-to-organic food intention}

The hypothesis stating that the consumer's higher motivation to elaborate further strengthened the effect of the consumers' positive attitude on the intention to switch ( $\mathrm{H} 6)$ supported on second level of hierarchical regression testing $(\beta$ $=0.1067 ; Z=23.3695 ; p=0.01)$. The test results support the hypothesis $(\mathrm{H} 6)$ and in line with the findings of previous studies (MaOz and Tybout, 2002; Chiu and Chiu, 2012). This suggests a moderating influence motivation to elaborate information on the pattern of relations a positive attitude with the intention of turning consumers switch to organic food.

Thus, the findings of a study on forming sequent practical intent of this switch also provides insights to marketers of organic food products on the importance of creating a stimulus to encourage the growth of consumer motivation to elaborate on the information and provide interesting information and adequate, with the hope to increase positive attitudes to switch so that in turn will increase the intention to switch to organic food.

\section{Conclusion}

At sequent formation of attitudes, the results showed that the factors forming attitudes switch to organic food is variable product attributes and inconvenience as well as motivation to elaborate information. In addition to elaborate motivation variables significantly contribute information as moderating the relationship between the variables of product attributes and inconvenience with an attitude switch. Moderating role of motivation variable information elaborates on the relationship with the product attribute variable switching attitude is strengthening ties to these two variables. Instead the role of moderating variables motivation to elaborate on the relationship variable information inconvenience obtain a product with an attitude switch is weakened ties to these two variables.

At sequent formation of intention to switch, the results showed that the factors forming the intention to switch to organic food is variable switching attitude and motivation to elaborate information. In addition to elaborate motivation variables significantly contribute information moderate the relationship between the variables of attitude switch with switching intentions. Moderating role of motivation variable information elaborates on the relationship with the intention of turning the attitude variable switch is strengthening ties to these two variables.

The theoretical implications of this study helps to understand the basic concepts of consumer switching behavior. From the perspective of an organic product marketers, need to create a stimulus that can encourage the growth of 
consumer motivation to elaborate on the information and provide interesting information and adequate, with the hope of improving understanding of related organic food products that have an impact on increasing positive attitude to switch which in turn will increase the intention to switch to organic food.

The switching intention model resulting from this study had been proved for its robustness theoretically and methodologically, but research laboratory experiments conducted in depth not discuss the behavior before and after treatment, therefore, future studies could follow up with an experimental design field so that the effectiveness of a given treatment will more real.

\section{References}

Ajzen, I and Fishben M. (1980). Understanding Attitudes and Predicting Social Behavior. Engelwood Cliftfs, New York: Prentice-Hall Ajzen, I. (1991). The theory of planned behavior. Organizational Behavior and Human Decision Processes, Vol. 50 No. 2, pp. 179-211. Ajzen, I. (2005). Attitudes, Personality and Behavior. (2nd edition), Open University Press-McGraw Hill Education, Berkshire, UK.

Anton, C., Camarero, C., and Carrero, M. (2007). Analysing firms' failures as determinants of consumer switching intentions, The effect of moderating factors, European Journal of Marketing, Vol. 41 No. 1/2, 2007 pp. 135-158

Armitage, C. J., and Conner, M. (2001). Efficacy of the Theory of Planned Behaviour: A meta-analytic review, British Journal of Social Psychology (2001), 40, 471-499.

Awogbemi., Oloda., and Osama. (2012). Modeling Brand Switching in Consumers' Products, Journal of Economics and Sustainable Development, Vol.3, No.12, 2012

Bansal, H. S. and Taylor, S.F. (1999), "The service provider switching model (SPSM): a model of consumer switching behaviour in the service industry", Journal of Service Research, Vol. 2 No. 2, pp. 200-18

Berry, L., Seinders, K., and Grewel, D. (2002). Understanding Service Convenience, The Journal of Marketing, Vol. 66, pp. 1-17.

Cacioppo, J., Petty, R., and Crites, S. (1994). Encyclopedia of Human Behavior, Academic Press, Inc, Vol I.

Campbell, D. T., and Stanley, J. C., 1966. Experimental and quasi-experimental designs for research. Boston: Houghton Mifflin Company.

Chan, C.C., and Tao, S.C., (2012). The Effects of Product Attribute's New Information on Consumer Elaboration and Brand Attitude, The Journal of International Management Studies, Volume 7, Number 1.

Chen, F.M. (2009). Attitude toward organik foods among Taiwanese as related to health consciousness, environmental attitudes, and the mediating effects of a healthy lifestyle, British Food Journal, Vol. 111 No. 2, 2009, pp. 165-178.

Chen, C. F. \& Chao, W. H. (2011). Habitual or reasoned? Using the theory of planned behavior, technology acceptance model, and habit to examine switching intentions toward public transit. Transportation Research Part F 14, pp 1280137

Chinnici G, D'Amico M, and Pecorino B. (2002). A multivariate statistical analysis on the consumers of organic products, British Food Journal, Vol. 14 No. 3/4/5/, 2002, pp. 187-199.

Chiu, C. C., and Chiu, T. S. (2012). The Effects of Product Attribute's New Information on Consumer Elaboration and Brand Attitude. The Journal of International Management Studies, Volume 7, Number 1, April, pp. 168-173.

Engel, J.F, Blackwell, R.D, and Miniard, P.W. (1992). Consumer Behavior. Dryden Press. Chicago.

Engle, R. (2001). GARCH 101: The Use of ARCH/GARCH Models in Applied Econometrics. Journal of Economic Perspectives-Volume 15, Number 4-Fall 2001-Pages 157-168.

Ertambang, N. (2012). Design and Implementation experiment research. UPP STIM YKPN. Yogyakarta.

Gerrard, P., and Cunningham, J.B. (2004). Consumer switching behavior in the Asian banking market, Journal of Services Marketing, Vol. 18 Iss: 3 pp. $215-223$.

Grace, D., and O'Cass, A. (2001). Attributions of service switching : a study of consumers' and providers' perceptions of child-care service deliver, Journal of Servives Marketing, Vol. 15 No. 4, pp. 300 - 321.

Grau, R., Salanova, M., and Peiro, J. (2001). Moderator Effects Of Self-Efficacy On Occupational Stress, Psychology in Spain, Vol. 5. No $1,63-74$

Grunert, K.G. (2002). Current Issues in the Understanding of Consumer Food Choice, Trends in Food Science \& Technology, Vol 13, No 8 (August), 275-285.

Gujarati, D.N and Porter, D.C. (2009). Basic Econometric, $5^{\text {th }}$ Edition McGraw-Hill/Irwin.

Gupta, S. and Ogden, D.T. (2009). To buy or not to buy? A social dilemma perspective on green buying, Journal of Consumer Marketing, Vol. 26 Iss: 6 pp. $376-391$

Harrel, G. (1986). Consumer behavior., Michigan State Unversity : Harcourt Brace Javanovich Publishers, New York.

Herr, P. M, Kardes, F. R, and Kim, J. (1991). Effects of word of mouth and product attribute information on persuasion: an accessibilitydiagnosticity perspective. Journal Of Consumer Research, Vol. 17. Pp. 454 - 462.

Homer, 1990. P. M. (1990). The Mediating Role of Attitude toward the Ad: Some Additional Evidence. Journal Of Marketing Research, Vol. 27. pp. $78-86$.

Kalafatis, S.P., Pollard, M., East, R., and Tsogas, M.H. (1999). Green marketing and Ajzen's theory of planned behaviour : a crossmarket examination, Journal of Consumer Marketing, Vol. 16 No. 5 1999, pp 441-460.

Keaveney, S.M. (1995). Customer switching behavior in service industries: an exploratory Study, Journal of Marketing, Vol. 59, April, pp. $71-82$. 
Kreitner dan Kinicki. (2008). Organizational behavior 10th edition. McGraw-Hill Ryerson, Thomson South-Western.

Lai, A. W. (1991). Consumption Situation and Product Knowledge in the Adoption of a New Product, European Journal of Marketing, Vol. 25 Iss: 10 pp. $55-67$

Lea, E and Worsley, T. (2005). Australians' organik food beliefs, demographics and values, British Food Journal, Vol. 107 No. 11, 2005, pp. 855-869.

Lee, K. W., Yuan, P.L., and Onchareon, W. (2012). The Study of Consumer Intention Toward Switch from Physical Book to e-book, http: //203.72.2.115/Ejournal/3093080202.pdf

Magnusson, M.K., Arvola, A., Hursti, U-K.,A Berg, L. and Sjo"de'n, P-O. (2001). Attitudes towards organik foods among Swedish consumers, British Food Journal, Vol. 103 No. 3, pp. 209-26.

Maoz, E and Tybout, A.M. (2002). The Moderating Role of Involvement and Differentiation in the Evaluation of Brand Extensions. Journal Of Consumer Psychology, 12(2), 119-131.

Moven, J.C and Minor, M. (1997). Consumer Behavior, 5th Edition, Prentice Hall, 696 pages.

Ninh, T.K.A., 2010. The role of consumer satisfaction, consideration set size, variety seeking and convenience orientation in explaining seafood consumption in Vietnam", Master Thesis in Fisheries and Aquaculture Management and Economics, The Norwegian College of Fishery Science University of Tromso, Norway \& Nha Trang University, Vietnam.

Olsen, S. O. (2007). Repurchase loyalty: The role of involvement and satisfaction. Psychology \& Marketing, 24(4), 315-341.

Ozcelik AO, Ucar A. (2008). Gender differences in adult's knowledge about dietary fats, cholesterol, fiber and energy. Pakistan Journal of Nutrition. 7(2): 234-239.

Petty, R. E., Ruker, D. D., Bizer, G. Y. and Cacioppo, J. T. (2004). The Elaboration Likelihood Model of Persuassion, Perspectives on Persuasion, Sosial Influence, and Compliance Gaining, Pearson, Boston, Chapter 5.

Rimal , A. P. and Fletcher, S. M. (2000). Influence of Product Attributes and Household Characteristics on Consumers' Attitude Toward and Purchase Pattern of In-shell Peanuts. Journal of Food Distribution Researc, November, pp. 28-36.

Saba, A. and Messina, F. (2003). Attitudes towards organic food and risk/benefit perception associated with pesticides, Food Quality and Preference, Vol. 14, pp. 637-645.

Savolainen, R. (2011). "Elaborating the motivational attributes of information need and uncertainty." Information Research, 17(2) paper 516. [Available at http://InformationR.net/ir/17-2/paper516.html]

Sheppard, B. H., Hartwick, J. and Warshaw, P.R. (1988). The Theory of Reasoned Action: A Meta-Analysis of Past Research with Recommendations for Modifications and Future Research. The Journal of Consumer Research, Vol. 15, No. 3. (Dec., 1988), pp. 325-343

Swanson, R. B. and Lewis, C. E. (1993). Alaskan direct-market consumers: perceptions of organic produce, British Food Journal, Vol 96(4):21-25.

Tarkianen, A. and Sundqvist, S. (2005). Subjective norms, Attitudes and Intentions of Finnish Consumers in Buying Organik Food, British Food Journal, Vol 107. No 11, pp. $808-822$.

Thapa, A. (2012). Consumer Switching Behaviour : A Study Of Shampoo Brands. National Monthly Refereed Journal Of Rconveniencearch In Commerce \& Management, Vol. 1, Issue no. 9. Issn 2277-1166.

Thøgersen, J. (2007). "Consumer decision making with regard to organik food products". in Vaz, M.T.D.N., Vaz, P., Nijkamp, P. and Rastoin, J.L. (Eds), Traditional Food Production Facing Sustainability: A European Challenge, Ashgate, Farnham.

Tung, S.J., Shih, C.C., Wei, S., and Chen, Y.H. (2012). Attitudinal inconsistency toward organic food in relation to purchasing intention and behavior, An illustration of Taiwan consumers, British Food Journal, Vol. 114 No. 7, pp. 997-1015.

Vindigni G., Janssen, M. A. and Jager, W. (2002). Organik food consumption, A multi-theoretical framework of consumer decision making, British Food Journal, Vol. 104 No. 8, pp. 624-642.

Wathne, K., Biong, H. and Heide, J.B. (2001). Choice of supplier in embedded markets: relationship and marketing program effects, Journal of Marketing, Vol. 65, April, pp. 54-66.

Wandel, M. and Bugge, A. (1997). Environmental concern in consumer evaluation of food quality, Food Quality and Preference, Vol. 8 No. 1, pp. 19-26.

Wen, Y. L. (2010). Customers Switch Behavior - A Case of Travel Agencies. Department of Managerial Economics, Nanhua University, 32, Chung Keng Li, Dalin, Chiayi ,Taiwan.

Weigel, R.H. (1983). Environmental Attitudes and the Prediction of Behavior, Praeger, New York.

Zanoli, R and Naspatti, S. (2002). Consumer motivation in the purchase of organic food. A means-end approach, British Food Journal, Vol. 104 No. 8, 2002, pp. 643-663. 